sand. I find it worrisome that there is currently a major move afoot to weld these two inimical worlds.

In this regard, I was surprised at the difference between the views of a natural philosopher and those of scientists I know on contemporary evolutionism and evolutionists. Abigail Lustig, in her chapter on natural athe- ology, actually suggests that most modern evolutionists may be "quiet theists of one kind or other." The unlikelihood of this notion is documented in a recent poll in which the overwhelming majority of prominent evolutionists reported themselves to be godless.

Lustig ends her chapter with a flung gauntlet of sorts: "The a priori belief in human exceptionalism provides one of the strongest, if unstated, criteria for judging the plausibility of evolutionary narratives. If we are no longer made in God's image, then in whose can we cast ourselves? In Darwin's?"

Lustig misses the main point: the evolutionist doesn't feel the need to cast himself in any image. That's what evolution is all about.

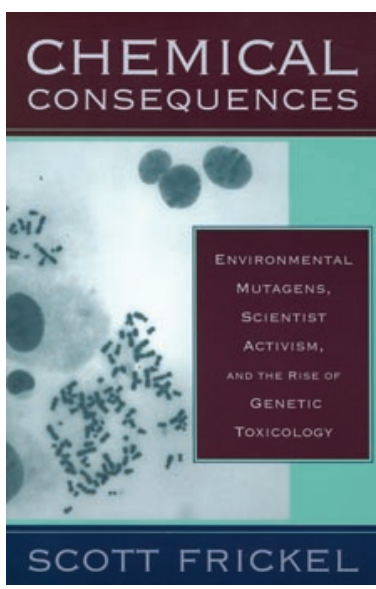

\title{
Chemical consequences
}

\section{Environmental mutagens, scientist activism, and the rise of genetic toxicology}

Scott Frickel

Rutgers University Press. New Brunswick, New Jersey, USA. 2004

224 pp. \$62.00. ISBN: 0-8135-3412-7 (hardcover).

224 pp. \$22.95. ISBN: 0-8135-3413-5 (paperback).

Reviewed by Jane $S$. Allen

E-mail: janeallentox@bellsouth.net he interdisciplinary science of genetic toxicology emerged in the 1960s as a result of a unique cross-fertilization of genetics and radiation biology. The talented, committed scientists who instituted this field of study were aided by new money, new laboratories, new environmental social activism, and new governmental interest. In his first book, Chemical consequences: environmental mutagen, scientist activism, and the rise of genetic toxicology, Scott Frickel, an assistant professor of sociology at Tulane University, explores the many factors that led to the establishment and development of this field through the late 1970s. With relevant and enlightening examples, the author illustrates how science and activism came together to establish what is now a major component of environmental health science.

Genetic toxicology today is a standard, although not always straightforward, component of regulatory toxicology testing required for FDA approvals of drugs and animal health products. It is also a regulatory tool used by the Environmental Protection Agency for evaluation of the hazards of pesticides and other environmental exposures. Its inclusion in standard toxicology testing programs is relatively recent, compared to testing for carcinogenicity, reproductive toxicology, and general toxicology. In addition, subdisciplines of genetic toxicology, involving, for example, DNA repair, infidelity of DNA replication, and mutation of specific genes are now recognized as having clinical importance in areas ranging from cardiovascular pathology to cancer.

Frickel writes from the perspective of a sociologist, not a historian or scientist. Accordingly, the material presented is a fascinating insight into how larger cultural factors were critical to the development of the field. Attaining a critical mass of scientific knowledge would have been useless in establishing a new field without the societal impetus. The book examines the establishment and interaction of interdisciplinary knowledge, funding, and careers. The emergence of genetic toxicology in the 1960s, a decade of massive transformation in American biology and in American culture as a whole, is well explicated. Frickel tracks how the field quickly moved from limited interactions among a handful of biologists to a full-fledged interdisciplinary science encompassing vigorous professional societies, scientific journals and publications, international conferences, and academic courses, which continue to this day. Of particular importance was the Oak Ridge National Laboratory, which provided an intellectual and physical home for much of the early work.

The first portion of the book succinctly discusses the scientific basis of genetic toxicology and nicely illustrates why this interdisciplinary field did not develop earlier, despite the fact that the guiding scientific principles had been clearly established. Frickel also explains why the initial emphasis was on environmental mutagenesis. That historical emphasis is reflected even today in the name of the premiere scientific association for genetic toxicology: Environmental Mutagen Society.

Frickel goes on to describe how the founding scientists as well as new recruits developed a type of environmental activism designed to be effective where it could have the strongest impact: within the research areas studied by the scientists on a daily basis. To explain the relevance of environmental mutagenesis to the public and to officials overseeing public health programs, they initially emphasized the need to preserve the integrity of the genetic code of future generations. Both scientific symposia and testimony before governmental agencies on the possible hazards of altering the gene pool gradually became less frequent. Eventually, carcinogenicity became a stronger, more common concern in genetic toxicology. Frickel provides a coherent description of this change in emphasis and its consequences.

While the writing style and presentation of data may appeal more to sociologists than to scientists, Frickel's insights regarding what is actually needed to develop a new scientific discipline are extremely interesting. 